\title{
Development four-band circular polarization patch antenna
}

\author{
Aleksandr Bezgin ${ }^{1, *}$ and Aleksandr Savochkin ${ }^{2}$ \\ ${ }^{1}$ Marine Hydrophysical Institute RAS, Sevastopol, Russia \\ ${ }^{2}$ Sevastopol State University, Sevastopol, Russia
}

\begin{abstract}
A combined four-band circular polarized patch antenna for the Argos-3 satellite communications system and GPS satellite positioning system of the L1 and L2 band is considered. The antenna provides operation circular right-handed polarization field in four frequency bands.
\end{abstract}

\section{Introduction}

To solve the problems of autonomous operational control of marine areas, in addition to organizing data transfer through communication channels, it is necessary to determine the coordinates of the object [1]. Next to the satellite communication system antenna, a receiving antenna of the coordinate determination system is installed for the purpose. To reduce the mutual influence of the antennas on each other, it is necessary to create a combined antenna. The proposed version of the combined antenna has two independent inputs: one input is intended for operation of a satellite communications system, the second for a GPS receiver. As a basis for the development, an implementation option of the dual-frequency Argos-3 antenna with one feed was used [2]. In most stand-alone devices, GPS receivers are used to determine the coordinates, which operate in the L1 band [3]. However, there are problems, the solution of which it is necessary to increase the accuracy of determining the coordinates. For this, GPS receivers operate in two bands L1 and L2 at once [4, 5].

\section{Antenna geometry}

The geometry of the combined Argos-3/GPS $\mathrm{L} 1+\mathrm{L} 2_{2}$ antenna is shown in Fig. 1. The antenna consists of a screen and four radiators located one above the other. Each radiator operates at its own frequency. The two lower radiators are located on dielectric substrates, the two upper ones are air-filled. To form circular polarization, the well-known method of cutting the angles of the radiators is used.

For research, we chose a cheap double-sided foil fiberglass FR4 with a thickness $\mathrm{h}=2$ $\mathrm{mm}$ and dielectric constant $\varepsilon=4$.4. Its disadvantage is the high dissipation factor $(0.02$ 0.03 ), which leads to decrease antenna gain. This can be corrected in further research by choosing a material for the antenna with a lower dissipation factor.

\footnotetext{
*Corresponding author: bezginaa@gmail.com
} 


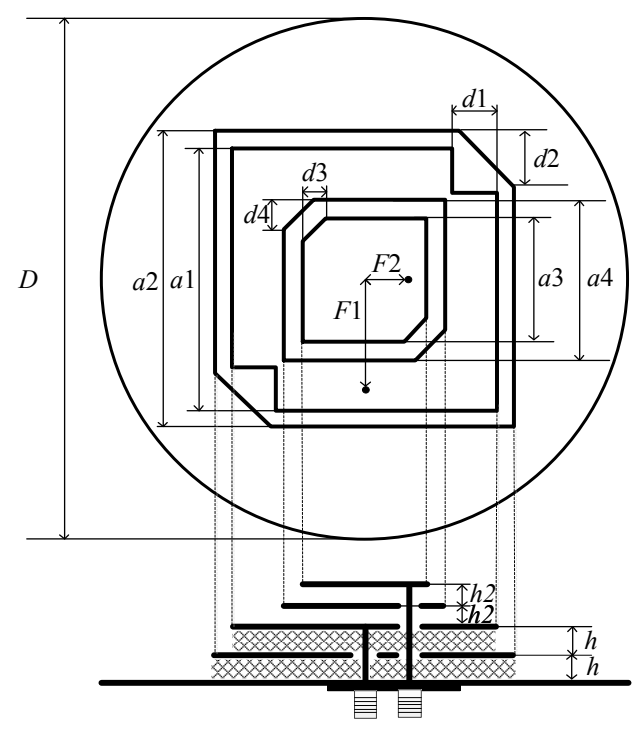

Fig. 1. Geometry of the combined Argos-3/GPS $\mathrm{L} 1+\mathrm{L} 2_{2}$ antenna.

The antenna model was created in CAD FEKO, where the geometric dimensions were clarified and the main characteristics were calculated.

The Argos- 3 radiator consists of two square radiators with dimensions a $1=158 \mathrm{~mm}$ and $\mathrm{a} 2=180 \mathrm{~mm}$ and a screen with a diameter $\mathrm{D}=400 \mathrm{~mm}$. The feed point is offset from the center by a distance of $F 1=72 \mathrm{~mm}$. The cutouts of the upper radiator are square in shape with dimensions $d 1=14 \mathrm{~mm}$. The cutouts of the lower radiator are made in the form of triangles with a side $\mathrm{d} 2=21 \mathrm{~mm}$. The geometric dimensions of Argos-3 radiators have not changed compared to [2]. GPS radiators with sides $\mathrm{a} 3=92.5 \mathrm{~mm}$ and $\mathrm{a} 4=12.3 \mathrm{~mm}$ are located above the Argos- 3 radiator at a height $\mathrm{h} 2=2 \mathrm{~mm}$. The cutouts are made in the form of triangles with sides $\mathrm{d} 3=7.5 \mathrm{~mm}$ and $\mathrm{d} 4=7.3 \mathrm{~mm}$. The GPS feed point is offset from the center by a distance $\mathrm{F} 2=20 \mathrm{~mm}$.

\section{Simulation and experiment results}

The simulated in CAD FEKO standing wave ratio (SWR) for Argos-3 and GPS are presented in Fig. 2. The SWR less than 2 is observed in the bands $399-411 \mathrm{MHz}$, $458-475 \mathrm{MHz}, 1262-1287 \mathrm{MHz}$ and $1555-1588 \mathrm{MHz}$.
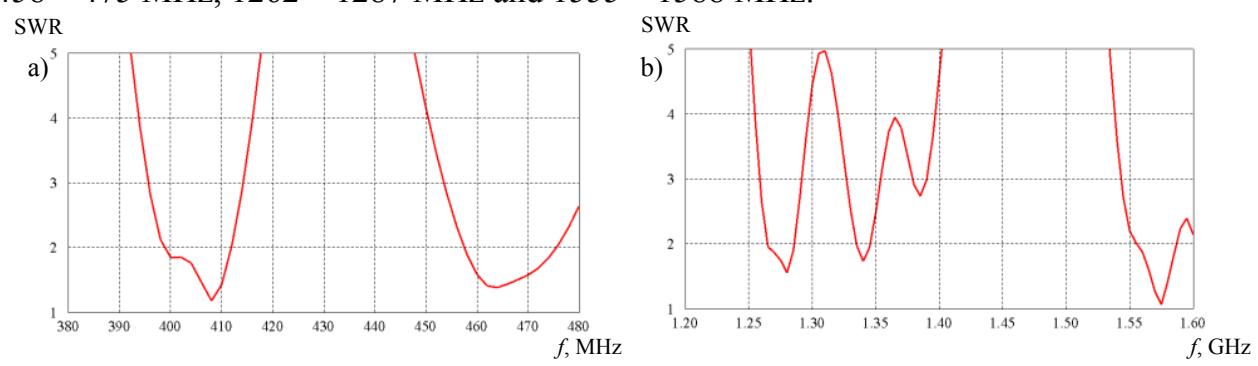

Fig. 2. Simulated SWR for Argos-3 band (а) и GPS band (b)

Simulated radiation patterns for right-handed and left-handed polarizations at Argos-3 band and $\mathrm{GPS}_{\mathrm{L} 1+\mathrm{L} 2}$ band are presented in Fig. 3. The gain difference between the righthanded and left-handed polarizations is at least $10 \mathrm{~dB}$. Simulated axil ratios are presented in 
Fig. 4. The radiation pattern information is summarized in table 1. The GPS gain is higher compared to Argos due to the larger ratio of wavelength to screen size. The antenna forms a weakly directed radiation with a field of right-handed circular polarization. The width of the antenna pattern meets the requirements for use in stand-alone marine measurement platforms [3].
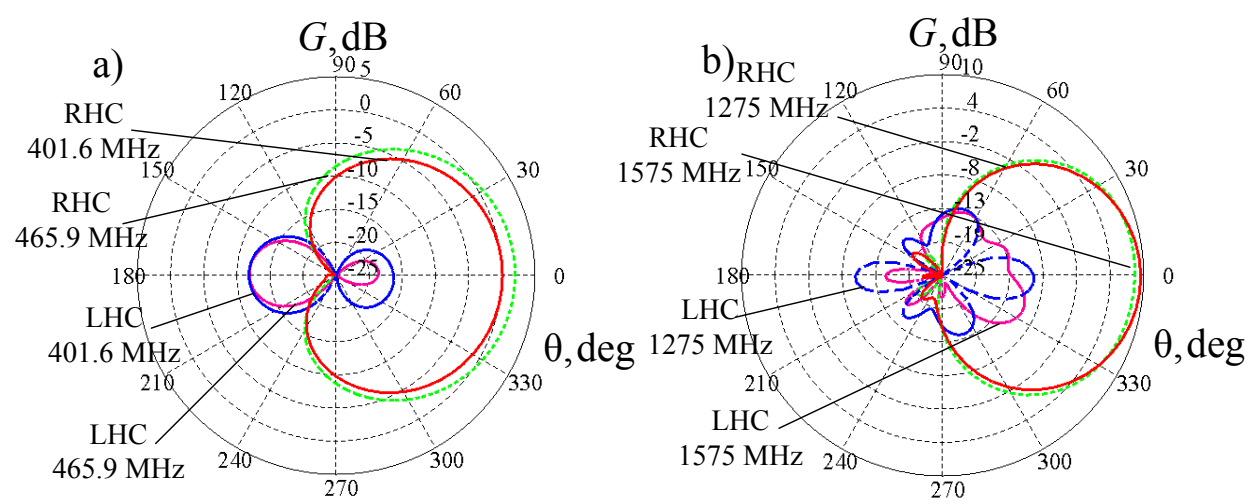

Fig. 3. Radiation pattern of the combined antenna at Argos-3 band (a) and $\mathrm{GPS}_{\mathrm{L} 1+\mathrm{L} 2}$ band (b) for right-handed (RHC) and left-handed (LHC) polarizations.
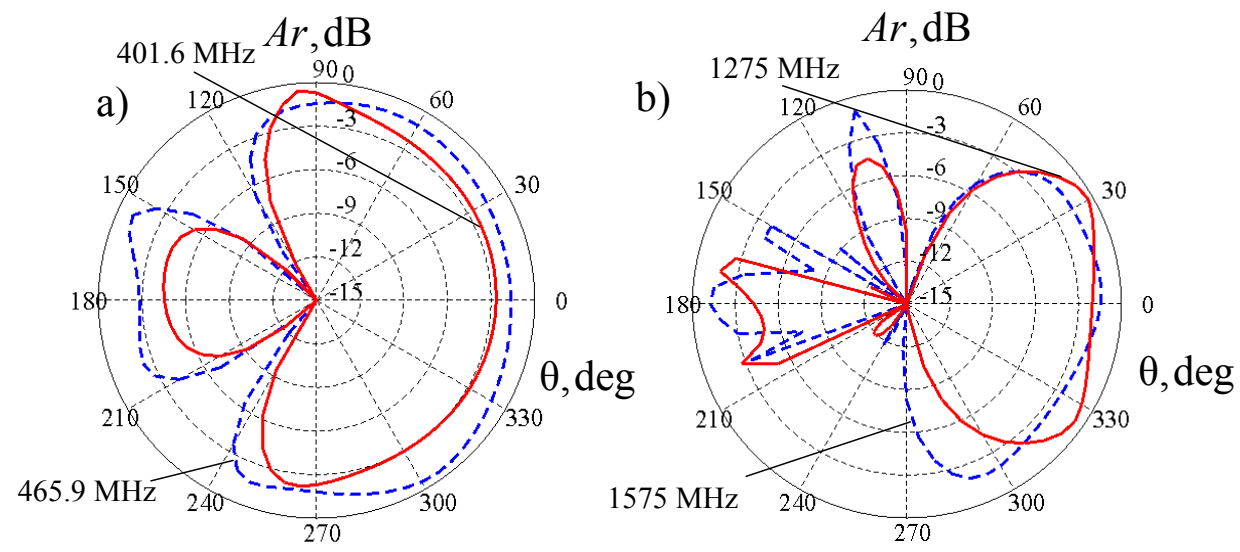

Fig. 4. The axial ratios of the combined antenna at Argos-3 band (a) and $\mathrm{GPS}_{\mathrm{L} 1+\mathrm{L} 2}$ band (b).

Table 1. Radiation pattern information

\begin{tabular}{|c|c|c|c|}
\hline $\begin{array}{c}\text { Frequency, } \\
\mathrm{MHz}\end{array}$ & Gain, $\mathrm{dB}$ & Axil ratio, $\mathrm{dB}$ & Beam width \\
\hline 401.6 & 2.8 & -2.7 & $100^{\circ}$ \\
\hline 465.9 & 4 & -2 & $108^{\circ}$ \\
\hline 1275 & 8.2 & -1.8 & $50^{\circ}$ \\
\hline 1575 & 9 & -1.5 & $54^{\circ}$ \\
\hline
\end{tabular}

Based on the simulation results, a four-level antenna prototype was created and an experimental study of the frequency dependence of the SWR was carried out (Fig. 5). The experiment confirms the existence of matching in four frequency ranges. The difference in experimental and model studies at the SWR level is due to inaccuracy in observing the geometric dimensions of the antenna prototype. 


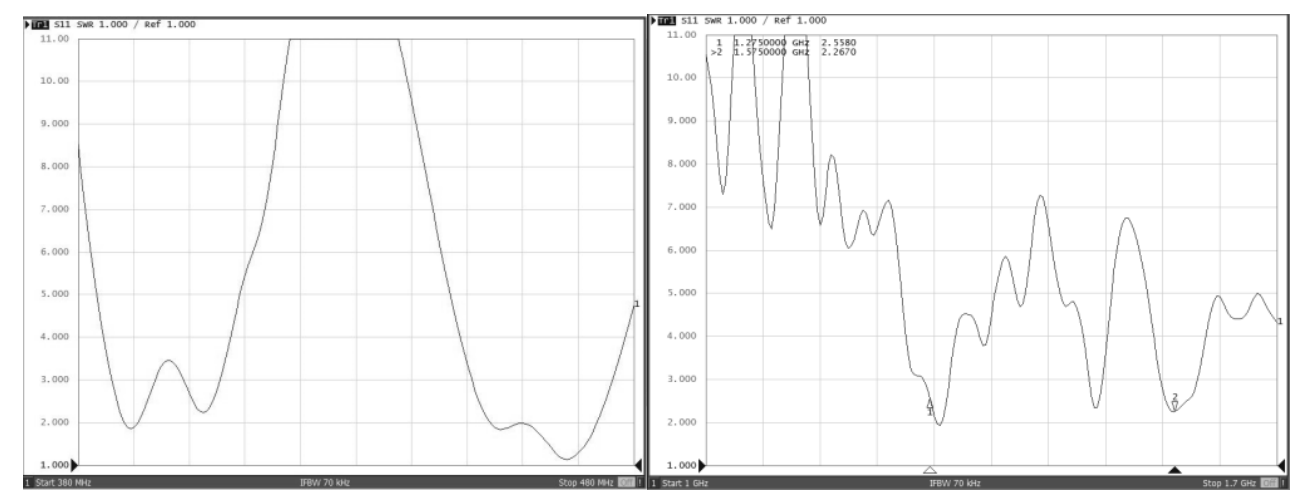

Fig. 5. Experimental SWR for Argos-3 band (a) и GPS band (b).

\section{Conclusion}

The possibility of creating multi-band combined antennas by installing radiators on top of each other is proved by modeling in CAD and experimental studies. Each radiator operates at its own frequency. It is proved that when the radiators are located one above the other, the polarization characteristics of each radiator are preserved. The developed combined Argos-3/GPS $\mathrm{L} 1+\mathrm{L} 2_{2}$ antenna forms a weakly directed field of right-handed circular polarization.

\section{References}

1. A.A. Bezgin, A.A. Savochkin, Patch Antenna for Satellite System Gonets, 2018 IEEE Conference of Russian Young Researchers in Electrical and Electronic Engineering, ElConRus 2018, pp. 459-460 (2018)

2. A.A. Bezgin, A.A. Savochkin, Two-band circular polarization antenna for Argos-3, 11th International Conference on Antenna Theory and Techniques, ICATT 2017, pp. 267-269 (2017)

3. S.V. Motyzhev, E.G. Lunev, V.A. Ivanov, A.G. Kirichenko, E. Lemeshko, Information-and-measuring drifter system for the monitoring of currents in the coastal zone of the sea, Physical Oceanography, vol. 20(5), pp. 366-378 (2011)

4. M. Chen, C. Chen, A compact dual-band (L1/L2) GPS antenna design, IEEE Antennas and Wireless Propagation Letters, no. 12, pp. 245-248 (2013)

5. X.F. Peng, S.S. Zhong, S.Q. Xu, Q. Wu, Compact dual-band GPS microstrip antenna, Microw. Opt. Technol. Lett., vol. 44, no. 1, pp. 58 - 61 (2005) 